\title{
El arte y la construcción del sujeto: una reflexión con Nan Goldin acerca de las narrativas familiares
}

\author{
Art and identity construction: \\ Reflections about family narratives with Nan Goldin
}

\author{
Oihana Garro-LARrañAgA \\ oihanagarro@gmail.com \\ Euskal Herriko Unibertsitatea - Universidad del País Vasco \\ Facultad de Bellas Artes
}

Recibido: 12 de marzo de 2013

Aceptado: 30 de septiembre de 2013

\begin{abstract}
Resumen
En este artículo se analizan las condiciones que posibilitan la construcción del sujeto contemporáneo a través del arte. Se formula el trabajo artístico como una herramienta que propicia la construcción del sujeto-artista en base a representaciones de liberación, diferenciándose de un sujeto contemporáneo construido únicamente en correspondencia a representaciones e instituciones de sujeción. Para exponer dicha cuestión se recurre al ejemplo de la narrativa familiar de la artista contemporánea Nan Goldin (Washington, 1953). Goldin ha realizado durante los últimos 40 años un diario visual en el que partiendo de fotografías familiares reflexiona sobre las características de la construcción identitaria. Entendemos aquí la identidad de Goldin como una identidad narrativa y nómada, que más allá de adoptar roles preestablecidos genera, sobre ciertos puntos parciales de anclaje, continuas transformaciones. Entendemos asimismo el arte que produce, como una obra abierta, deconstructiva, narrativa y desgarrada. Sostengo que dichas construcciones artísticas e identitarias se alimentan mutuamente.
\end{abstract}

Palabras clave: Sujeto desgarrado, narrativas familiares, identidad narrativa, identidad nómada, construcción de la identidad.

Garro-Larrañaga, O. (2014): El arte y la construcción del sujeto: una reflexión con Nan Goldin acerca de las narrativas familiares. Arte, Individuo y Sociedad, 26 (2) 255-269

\begin{abstract}
This article analyzes the conditions that enable the construction of the contemporary subject through art. I argue that the artistic work is a tool that permits the construction of the artist not only on the basis of institutions and representations of subjection, but also of representations of liberation. In order to analyze this process, I focus on the family narrative of contemporary artist Nan Goldin (Washington, 1953).
\end{abstract}


Over the last forty years Goldin has crafted a visual diary in which she reflects on the characteristics of identity construction through family photos. I understand Goldin's identity as both narrative and nomad. Though momentarily anchored in partial points, this identity does not adopt pre-established roles and is continuously in flux. I consider the art she produces as an open, deconstructive, narrative and lacerated work, and contend that these artistic and identity constructions are closely intertwined.

Keywords: lacerated subject, family narratives, narrative identity, nomad identity, identity construction.

Garro-Larrañaga, O. (2014): Art and identity construction: Reflections about family narratives with Nan Goldin Arte, Individuo y Sociedad, 26 (2) 255-269.

Sumario: 1.Introducción, 2. Nan Goldin: representación y recreación de la narrativa familiar, 3. La construcción del sujeto moderno 3.1. Orden versus Caos, 3.2. La importancia del espacio biográfico), 4. La construcción del sujeto contemporáneo, 5. Metodología de análisis, 6. La construcción de Nan Goldin, 7. A modo de conclusión. Referencias.

\section{Introducción}

Comencemos visionando una serie de tres imágenes sin clara analogía entre ellas, al menos a primera vista. La primera imagen es una reproducción actual del Partenón de Atenas; la segunda, la fotografía Nan one month after been battered (1984) de la fotógrafa estadounidense Nan Goldin; y la última, una imagen del edificio Schlesisches tor Housing del arquitecto Alvaro Siza en Kreuzberg, Berlín. El rostro golpeado de Goldin se representa entre el templo dórico demacrado o glorificado por el paso del tiempo y el agujero-ojo Bon Jour Tristesse que perfora o completa de significado la fachada de la vivienda social; es un autorretrato de la artista mirando de frente, erguida y con los labios rojos. El hecho de ver la fotografía de Goldin en una serie inusual, visionarlo en una relacionalidad otra, genera una nueva percepción del objeto. Así, volvemos a mirar un retrato ya visto, retrato que simboliza a una mujer, Nan Goldin, desgarrada. Dice Didi-Huberman que el ser humano desgarrado "sólo piensa en cuanto dividido, desgarrado, destinado a la muerte" (Didi-Huberman, 2010:281).

En este artículo, con la fotografía Nan one month after been battered, se analizan las condiciones que posibilitan la construcción del sujeto contemporáneo a través del arte. Para ello nos referimos necesariamente a las relaciones entre arte e identidad, identidad y arte; concibiendo la identidad contemporánea no como un hecho fáctico, sino como un potencial abierto en continuo proceso de construcción (Gómez, 2012). Así, nos preguntamos si puede el artista construir su subjetividad, diferenciándose en alguna medida de las categorizaciones identitarias dominantes o los procesos de apropiación pre-establecidos. Es decir, volviendo a nuestro caso, la pregunta sería: ¿participa Nan Goldin activamente en la construcción de su identidad?

Para profundizar sobre la posibilidad de construcción del sujeto artista a través del arte se manejan dos herramientas analíticas principales: la primera consiste en reconocer los parámetros culturales y sociales en los que nos situamos para luego poder reformularlos. Esta acción exige trabajar las representaciones desde dentro, teniendo en cuenta su carácter textual y en la forma que Derrida denomina deconstrucción. Porque consideramos que no es posible intervenir desde un afuera; pero sí 
problematizar desde dentro las relaciones de representación dominantes y provocar en definitiva nuevas lecturas que nos permitan pensar y mejorar la textualidad existente. Por consiguiente, la deconstrucción "es más bien una forma de hacer violencia a las ideas habituales de método, aplicando los métodos mismos hasta sus límites" (Torregroza, 2004: 26).

La segunda herramienta es la interdisciplinaridad, es decir, la defensa de una relación constante y constitutiva entre la representación artística y otras representaciones, más o menos poderosas, porque entre ellas construyen las redes que configuran la realidad y al sujeto contemporáneo. El artista no construye su identidad únicamente en relación a la representación artística, sino que en su construcción identitaria actúan múltiples representaciones (políticas, sociales, filosóficas, biográficas, etcétera).

\section{Nan Goldin: representación y recreación de la narrativa familiar}

Arthur Rimbaud anunció en 1871 el descentramiento del sujeto esencialista moderno con su frase "Nos equivocamos al decir yo pienso; deberíamos decir; me piensan (...) Yo es otro". La enunciación de Rimbaud, Yo es otro, indica la importancia de la presencia del otro en la construcción de la identidad, indica la importancia de la apertura; y abrirse al otro es una característica fundamental del trabajo de Nan Goldin y lo es también de la concepción de identidad y arte que se plantea en el presente estudio.

Nan Goldin constituye un ejemplo paradigmático de una artista que fotografía insistentemente a su familia, lo que acostumbra a ser el primer grupo relacional de las personas o la primera apertura al otro. No obstante, Goldin no es la única artista que ha realizado representaciones sobre su familia. La lista de artistas que han trabajado la narrativa familiar es extensa: Sally Mann, Tina Barney, Larry Sultan, Yuire Nagashima, Angela Strassheim, Bill Owens, Richard Billingham, Darren Almond, Mira Bernabeu, Hans-Peter Feldman, Santu Mofokeng, Inmaculada Salinas, Jo Spence, Mario de Ayguavives, Norbert Becwar, Hiroshi Sugimoto, Dorothea Lange, Enrique Marty, Mitch Epstein, Sebastian Friedman, Jim Goldberg, Oriana Eliçabe, Elliott Erwitt... No obstante, una característica distingue a Goldin del resto de los artistas mencionados: la proyección temporal de su trabajo, pues lleva fotografiando a su familia durante más de 40 años. Es por ello una artista especialmente apropiada para analizar, desde la representación y recreación del álbum familiar en el arte, la cuestión dialógica entre la construcción de la obra de arte y la construcción de identidad.

Nan Goldin nace en Washigton en 1953 y comienza a sacar fotografías a raíz de la muerte de su hermana Barbara. Barbara Holly Goldin se arroja a las vías del tren en 1965, cuando Goldin tiene once años. Lo importante, escribe Goldin, es que nadie sepa lo que ha ocurrido (Goldin, 1997). Nacida en una familia revisionista, las paredes de la casa familiar, el espacio privado, tienen que esconder el hecho del suicidio.

De modo que Goldin empieza a fotografiar después de una muerte particular, la de su hermana, pero lo hace, además, en un contexto más amplio de muertes. Un contexto en el que se da, en palabras de Lyotard, la muerte de los Grandes Relatos de emancipación, entre ellos, el Estado, la Metafísica o la Familia. Para Lyotard Gran 
Relato o Metarrelato es aquel relato que adquiere una función legitimante o legitimatoria y pretende ordenar bajo sus parámetros los acontecimientos de la vida; de modo que, se cree ya no un relato, sino una realidad verdadera destinada hacia la absolución total de la humanidad (Lyotard, 2003:31). En estos momentos, por tanto, Goldin habita, tanto en su experiencia más particular como en su experiencia más colectiva, un escenario herido, insistimos en el concepto de Didi-Huberman, desgarrado.

Después del suicidio de su hermana Barbara, Goldin abandona temporalmente su familia sanguínea y vive en sucesivas comunas en las que encuentra una nueva familia. A los 18 años se traslada, junto con su amigo David Amstrong a Boston y es allí cuando en un bar llamado The Other Side comienza a fotografiar a sus compañeros de piso que participan travestidos en el concurso de belleza de The Other Side. Indisociables a la decadencia de los Metarrelatos emergen múltiples microrelatos o pequeñas historias, relatos de mujeres, homosexuales o drags que reivindican a su vez un lugar en la historia. Y en este sentido Goldin, afín a unos deseos propios del contexto temporal en el que vive, dice que quiere ser una fotógrafa de moda para que las fotografías que realiza de sus amigos drag-s aparezcan en la portada del Vogue (Goldin, 1993:9). De manera que, múltiples factores contextuales — las miradas de los otros más cercanos, la muerte de una hermana, el reduccionismo del espacio privado, la crisis de los grandes relatos, la propulsión de las pequeñas historias, entre otros- construyen a un sujeto Goldin altamente determinado por el contexto que habita.

\section{La construcción del sujeto moderno}

El sujeto siempre está sujeto a lo que le rodea, sujeto a una realidad atestada por millones de representaciones. De modo que se rechaza una forma esencialista y universal del sujeto, puesto que éste se constituye a partir de prácticas de sujeción que lo transforman continuamente. Es importante pensar en las consecuencias históricas que determinan al sujeto, para así poder proponer ciertas alternativas de solución; es decir, para que un sujeto además de estar construido por prácticas de sujeción, representaciones de sujeción, también pueda elaborar prácticas de liberación, representaciones de liberación, que le permitan mantener el carácter de su diferencia a pesar de todo. En definitiva, no sólo estar hechos por, sino también poder hacerse y, como escribe Foucault, poder ejercer cierto "gobierno sobre sí mismo" (Foucault, 2002).

Hemos dicho que el sujeto está construido por el contexto, de modo que, para poder plantear a posteriori algunas posibles formas de transformar lo dado es imprescindible conocer su especificidad, su marco constitucional. Con este fin analizaremos ciertas representaciones que configuran la identidad del sujeto contemporáneo para luego poder, desde el arte, plantear algunas identidades más intencionales o autogobernadas.

Conocer al sujeto contemporáneo, comprenderlo como una consecuencia histórica y describirlo en su actualidad, demanda revisar sus genealogías. "Busquen el origen en los mitos modernos" escribe Latour (Latour, 2007:181). Especifiquemos que en este apartado no queremos acometer una historia de la identidad, dónde se incluya 
la genealogía de la identidad moderna, sino que se ha elaborado un abanico analítico, posible entre otros, que después vincularemos a la obra-vida de Nan Goldin.

\subsection{Orden versus Caos}

En referencia a la construcción del proyecto moderno son conceptos clave el orden y el caos; el orden es conceptualizado por la modernidad como estandarte de su ideal y el caos como "lo otro del orden. El hedor de lo indeterminado o impredecible" (Bauman, 2005:26). Los tropos del caos son, la indeterminación, la incoherencia, la incongruencia, la ilogicidad, la irracionalidad, la ambigüedad, la confusión, la indecibilidad o la ambivalencia. Y por ello, el caos advierte continuamente sobre la necesidad de control y estructuración de la realidad, es decir, el caos sólo existe en cuanto que promueve la necesidad de orden. La existencia es moderna, escribe Bauman sobre esta cuestión, en cuanto que contiene las dos alternativas: orden y caos; ambos conceptos son interdependientes, ya que no puede haber orden sin caos, ni caos sin orden.

Sobre este fundamento planificador de la modernidad, Foucault define los marcos de una sociedad disciplinaria. Según el autor instituciones tales como psiquiátricos, escuelas o prisiones ejercen un poder coextensivo que se expanden por toda la sociedad y pretenden, al fin y al cabo, que ningún acto del sujeto escape a su control (Foucault, 2010). De manera que, el plan de orden moderno pretende establecerse como resultado de la suma de muchas pequeñas partes ordenadas.

Además de las instituciones aludidas por Foucault, destacamos con Taylor la importancia que han tenido ciertas representaciones o Grandes Relatos a la hora de establecer dicho orden (Taylor, 2006). Entre estas representaciones sobresale el poder de la filosofía Metafísica como generadora de los sentidos de la vida moderna. Subrayamos con la Metafísica el gran cambio que supone el paso de un orden premoderno y cósmico, que se encuentra fuera del sujeto, a un orden moderno y creado por el sujeto que se localiza en su interior, reconocible claramente en Descartes. Por lo tanto, la realidad a partir de Descartes es el resultado de la acción del sujeto, de su juicio. Tras ese momento, la metafísica es el paradigma de esa acción organizativa, de forma que la realidad se construye como un sistema relacional que se fundamenta en una estructura de oposiciones: interior/exterior, mente/cuerpo, significado/forma, positivo/negativo, transcendental/empírico. Esta estructura binomial es jerárquica y mientras el primer término supone una presencia superior, el segundo surge como resultado, efecto o desbordamiento del primero.

Con la aparición de fotografía poco a poco la representación visual va cobrando protagonismo en la modernidad. Se empieza a convivir con las imágenes y puede decirse que el poder de la metafísica, de la palabra escrita, como fundamento definitorio de la vida va decreciendo a favor de un entendimiento de la realidad a partir de la imagen. Heidegger escribe en La época de la imagen del mundo que la realidad se convierte a partir de la modernidad por completo en una imagen (Heidegger, 2001:72). El mundo como texto, señala sobre esta cuestión Mierzoeff, ha sido sustituido por el mundo como imagen (Mirzoeff, 2003), la práctica fotográfica propicia la codificación visual de la realidad. 
Para entender las características de la imagen en la modernidad, sin embargo, hay que remontarse al Renacimiento. En aquella época se concibe la realidad como un orden dispuesto cósmicamente, sin embargo, a través de la técnica de la perspectiva ya se manifiesta una nueva responsabilidad del sujeto-artista en la categorización de la realidad. La técnica de la perspectiva sitúa al artista en un lugar privilegiado, ante una ventana, comprendiendo la mirada como una posesión de la realidad visible de las cosas. Antich considera que "la perspectiva como forma simbólica, más que un simple estadio en el dominio técnico de la representación de lo visible, supone quizás la estrategia plástica de mayor envergadura por organizar todo el territorio de las formas visibles en torno al ojo que, mirando las cosas, acaba por poseerlas" (Antich, 2007:94).

Siguiendo esta línea de comprensión de la mirada, ya avanzada la modernidad, subrayamos la imagen fotográfica como mecanismo de aprehensión de la realidad. Las transformaciones acontecidas en la producción y recepción de las imágenes, de la imagen original a la imagen reproducida técnicamente (Benjamin: 2007), no cambian en esencia la conceptualización de la imagen como forma de control inaugurada en el Renacimiento. Es más, la nueva condición adquirida aumenta la acción de esa maniobra y la imagen - imagen/control para Antich - se convierte según el autor en principal instrumento institucional de control social, ya que permite el primer archivo, de criminales, delincuentes y otras gentes supuestamente peligrosas. Es decir, a partir de la popularización de la fotografía, se construye una nueva mirada sobre la realidad y se inicia la era de la representación visual de un mundo clasificado, ordenado y tipificado por la imagen. Junto con la democratización de la imagen, deviene también, tal lo predijo Heidegger, la creencia de poder poseer la realidad a través de la misma.

\subsection{La importancia del espacio biográfico}

La modernidad, evidentemente, también define clasificatoriamente al sujeto, y éste se articula como sujeto individual o sujeto social. Así pues, para hablar del individuo, es necesario hacer referencia a la sociedad, caracterizada por la rigidez de su estructura, en cuyas cualidades el individuo es identificado, pero no se identifica (Gómez, 2012). Ello nos lleva directamente a reconocer en la sociedad dos esferas físicas bien diferenciadas: la esfera privada, propia del sujeto individual y la esfera pública, propia del sujeto social.

El sujeto, al convertirse en individuo o en sociedad, necesita establecer una forma de vincular una esfera con la otra, cuestión que se simboliza claramente en el auge de las representaciones biográficas. El sujeto individual, actor principal en la esfera privada, precisa publicitarse en el espacio público y ello provoca la propulsión del espacio biográfico; proliferan las autobiografías o los retratos y fotografías familiares. Arfuch escribe que "la aparición de un yo garante de una biografía es un hecho que se remonta apenas a poco más de dos siglos, indisociable al afianzamiento del capitalismo y del orden burgués" (Arfuch, 2002:33). Son tecnologías del yo analizadas por Foucault que surgen desde la ilusión de un sujeto que cree poder contarse en el texto como un todo reunido.

Ajustándonos a la práctica fotográfica, con el acceso por primera vez en la historia a la fotografía, muchos individuos logran la posibilidad de inmortalizarse. Y la 
posesión de la propia imagen aviva el sentimiento del sujeto de poseerse a sí mismo. La representación del individuo acontece junto con la representación de su grupo relacional más próximo, la familia. A medida que se extienden los retratos, los álbumes familiares, como advierte Benjamin, comienzan a llenarse (Benjamin, 2005) y se instituye, en palabras de Sontag, el primer uso social de la fotografía: la fotografía personal y familiar (Sontag, 2005). La conmemoración de las acciones de los individuos, en tanto que individuos pertenecientes a la privacidad de una familia, genera un inter-espacio, privado-público, pues comúnmente las fotografían se visionaban en el salón de la casa, lo que se considera el espacio más público del espacio privado.

El álbum familiar acostumbra a representar la idea de una apariencia feliz y unida, una imagen de la familia como un grupo compacto y sin fisuras que le confiere al individuo su primera colectividad donde identificarse. Benjamin subraya que éste fenómeno es parejo a la consolidación de la clase social burguesa de mediados del siglo XIX. Para registrar dichas apariencias familiares, por una parte, en relación a la necesidad representativa y simbólica del tiempo de la modernidad, el álbum ordena el tiempo en una perspectiva lineal, donde pasado, presente y futuro se alinean en un continuum temporal progresivo. Por otra parte, las imágenes realizadas en base al prototipo de belleza de la época (rasgos suavizados, semblantes lisos, imagen atenuada) y escenas sobre-escenificadas (un telón pintado donde se simula un paisaje, una balaustrada, un lujoso cortinaje de terciopelo) construyen estampas ceremoniosas donde se inmortalizan unos sujetos altamente codificados. Representaciones, en definitiva, de individuos y primeras colectividades pertenecientes a una sociedad que admira el orden y que hace uso de la fotografía para promocionarlo.

\section{La construcción del sujeto contemporáneo}

La ideación del sujeto moderno esencial, en relación siempre con la ideación del orden, es por excelencia la forma o representación de la modernidad. Y es precisamente el escepticismo hacia esa forma de la modernidad lo que caracteriza al sujeto contemporáneo. Sujeto que habita un periodo que ya no puede pensarse en términos de orden, ni proyectarse en términos binomiales. De modo que, describiendo la contemporaneidad por medio de la metáfora de Bauman, diríamos que vivimos en una realidad fluida; un tiempo líquido que sufre continuas fluctuaciones o cambios (Bauman, 2007)

Asimismo, la aparición de los híbridos cuasi-objetos, cuasi-sujetos, rompen radicalmente el esquema organizativo moderno; todo está interrelacionado, nada está ya ordenado. En la contemporaneidad se crean redes o madejas relacionales en las que las historias se entretejen unas con otras. Latour escribe que "los cuasi objetos siguen proliferando, esos monstruos de la primera, de la segunda, de la tercera... revolución industrial, esos hechos socializados y esos humanos convertidos en mundo natural. Cerradas de inmediato las totalidades se resquebrajaban por todas partes. Los fines de la historia, a pesar de todo, dan curso a la historia" (Latour, 2007:89).

Hemos dicho que los mecanismos de disciplinamiento modernos (la escuela, la fábrica, la familia, etcétera) construían un sujeto bien definido tanto en su colectividad como en su individualidad. En contraste, en la contemporaneidad, las estructuras 
del poder ya no están tan delimitadas. Es decir, las estructuras colectivas de enraizamiento identitario no significan lo suficiente para que el sujeto contemporáneo pueda enraizar su subjetividad permanentemente en ellas. Esta dificultad genera la imposibilidad de que el sujeto se afirme, durante un largo tiempo, como parte de una colectividad. El binomio individuo- sociedad se desvanece. Es decir, citando a Deleuze "estamos en una crisis generalizada de todos los lugares de encierro: prisión, hospital, fábrica, escuela, familia. La familia es un "interior" en crisis como todos los interiores. Los ministros competentes no han dejado de anunciar reformas supuestamente necesarias. Pero se sabe que estas instituciones están terminadas, a más o menos corto plazo. Sólo se trata de administrar su agonía” (Deleuze, 1991).

Como consecuencia de esta instalación progresiva y dispersa de un nuevo régimen de poder fluido, que Deleuze denomina Sociedad de Control, y desde el reconocimiento de la dificultad de pensarse como parte de un colectivo, es difícil que actualmente exista un sentido de arraigo en lo común. El sentimiento de desarraigamiento es el sentimiento de la contemporaneidad y ante este desarraigamiento, las nuevas formas del poder atribuyen la tarea de la construcción de la identidad al propio individuo. Dicho en otras palabras, es el sujeto en su individualidad, en su soledad, quién asume el deber de autoconstruirse. Otra de las características de este sujeto contemporáneo, en relación a la representación biográfica, es la dificultad de decir yo, es decir, la crisis de su autoría. Es imposible que una representación biográfica condense la experiencia de vida del autor, pues su identidad no se mantiene ya siempre igual a sí misma. Es una identidad fluctuante que se manifiesta en unas narraciones que son incapaces de representarlo como un todo unitario y compacto. El sujeto que en la modernidad se dibujaba como unificado y entero, en la contemporaneidad es un sujeto que debe buscar nuevas formas de representación que lo representen.

De modo que la identidad fija y estable se convierte en un proceso abierto que cambia a lo largo de toda la vida. Identidades contemporáneas, múltiples, incompletas, desgarradas... que conviven en el sujeto, provocando tensiones, cambios y contradicciones constantes. Consideramos la identidad que deriva de este proceso una identidad nómada en términos de Braidotti y una identidad narrativa en términos de Ricoeur. Son nómadas aquellas identidades que perturban al sujeto unitario, esencial e igual a sí mismo, reconocen su movilidad y performatividad, pero al mismo tiempo, buscan ciertos puntos parciales de anclaje para, aunque sea estratégicamente, seguirse representando (Braidotti, 2004). Son narrativas las identidades que tienen que encontrar fundamentalmente sus modos de decirse, reconociendo el carácter constructivo de éstos. "Una historia que tiene que ver a veces con hechos reales, a veces no, pero que luego pasa a ser realmente tu propia historia" (Robin, 1999:52). Y es aquí donde volvemos a aludir a la relación arte e identidad, identidad y arte.

\section{Metodología de análisis}

Después de referirnos a los marcos constitutivos del sujeto y conociendo ya la especificidad del sujeto contemporáneo, vamos a analizar a continuación la posibilidad de construcción de este sujeto a través del arte. Entendemos que la identidad del sujeto que participa de esta acción constitutiva, no sólo se construye a partir de prácticas 
de sujeción, sino también a partir de prácticas de liberación. Para ello, como ya se ha dicho, analizaremos la fotografía Nan one month after been battered de la artista estadounidense Nan Goldin desde distintos puntos de vista.

Metodológicamente nos hemos decantado por analizar la fotografía en los libros de la artista y no, por ejemplo, en sus exposiciones; decisión que se ha tomado por la accesibilidad y transportabilidad del formato libro. Además, consideramos que para Goldin el libro editado no significa "simplemente" la documentación o catalogación de su obra, sino que constituye en sí mismo una estructura de acceso. Afirmamos que Goldin, evocando una autodefinición de la propia artista, más que una fotógrafa es una narradora. Los libros de Goldin ofrecen la posibilidad de la asociación entre libro, narración, autor y lector; en una era en la que, pronostica Benjamin, el arte de narrar está desapareciendo junto con el fracaso de la cotización de la experiencia.

Para concebir la construcción de la identidad nómada a través de la obra de Goldin, y comprender la interrelación identidad/arte que se da en ella, hemos analizando la fotografia Nan one month after been battered, por un lado, examinando cómo Goldin presenta la fotografía en los libros en la que Nan one month after been battered aparece: The beautiful Smile (2007); Couples and Loneliness (1998), Nan Goldin. I'll be your mirror (1996), The ballad of the sexual dependency (1986). La característica principal de todos estos libros es que están editados por un grupo liderado por la propia artista, lo que en definitiva se construye en los libros es la selección realizada por Goldin.

Elegimos empezar con The Beautiful Smile por ser su último libro editado hasta el momento, nos importa la contemporaneidad de su sujeto y también de su obra. Queremos subrayar la importancia de la Goldin actual, en relación directa con la insistencia marcada por conocer la particularidad del sujeto contemporáneo. Por ello, analizaremos los libros desde los más recientes a los más antiguos, de modo que profundizaremos en los distintos extractos de la construcción de su identidad en un orden cronológico inverso. Por otro lado, se ha relacionado la fotografía Nan one month after been battered y su edición con experiencias de la vida de Nan Goldin, experiencias que recogemos de testimonios de los propios protagonistas. Esta fotografía nos permite recorrer su vida desde la época en la que comenzó The ballad of the sexual dependancy, a mediados de los años ochenta del siglo pasado, hasta la actualidad, la exposición Nan Goldin-Berlin Work Fotografien en 2011.

\section{La construcción de Nan Goldin}

Uno de los principales objetivos de este estudio es reconocer la posibilidad de construcción del artista a través del arte, y para ello se ha partido del análisis de las diferentes ediciones de la fotografía Nan one month after been battered, recordando la potencialidad que adquiere la fotografía al cambiar la edición en la que se presenta. Para iniciar el análisis de las diferentes ediciones observamos la colocación de la fotografía en el libro The Beautiful Smile del año 2007.

En "The Beautiful Smile" (2007) Nan one month after been battered aparece tras la pintura mural en la que una mujer arranca un ojo a un monstruo, cuando el monstruo intenta estrangularla y una serpiente acecha por detrás. Brian es el agente del 
golpe. Es la primera foto de The Beautiful Smile donde aparece Goldin enfocada. El color rojo del ojo, el color rojo del labio, el pelo rizado de la artista se articulan con el ojo rojo arrancado del monstruo, el pelo rizado de la heroína del mural.
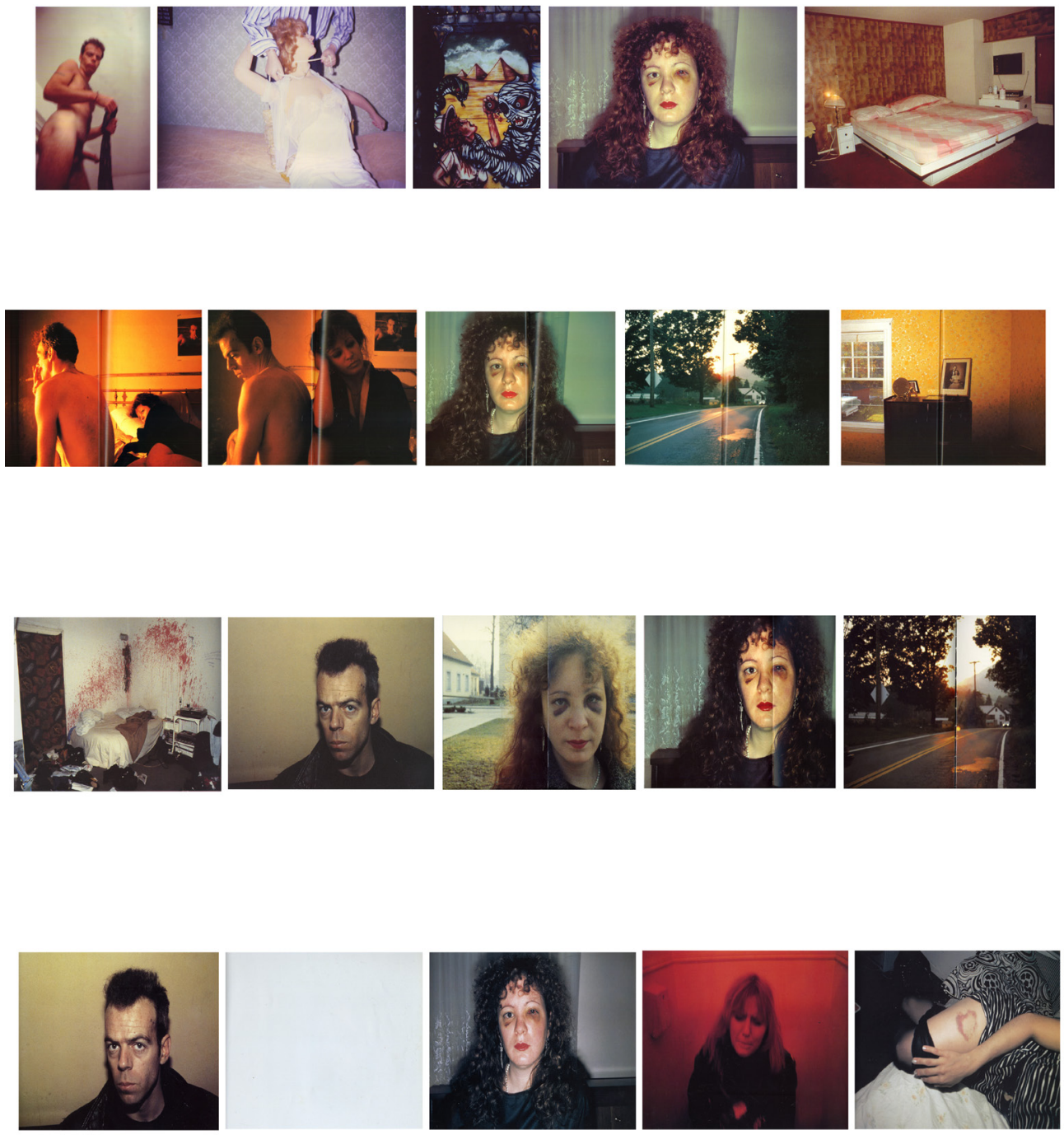

Goldin establece partiendo de su inmenso archivo de imágenes - recordemos que lleva más de 40 años sacando fotos a su familia - qué narrativas se inscribirán y cuáles no. Este procedimiento nos posibilita comprobar que variando la edición de 
las imágenes, utilizando las mismas imágenes ordenadas de distinta forma, modifica la narrativa que presenta. Cada narrativa representa diferentes experiencias de la vida familiar de Goldin, o las mismas experiencias asimiladas de diferente manera. Hemos dicho que Goldin dice que ella más que una fotógrafa es una narradora y entendemos que narrar es contar historias, es decir, intercambiar experiencias. En este sentido, cada narración (exposición, slide-show, libro editado por la artista) presenta en el caso de Goldin una nueva edición de las fotografías. Es decir, la artista acostumbra a repetir ciertas fotografías de su vida, pero no repite la edición de éstas. Las ediciones, asimismo, no se ordenan cronológicamente. Las narraciones biográficas no ordenan ideológicamente el pasado siguiendo un patrón temporal clásico; por ejemplo, en The Beautiful Smile, la edición es la siguiente: Brian with the rope, NYC 1983 - Wax museum, Coney Island, NY 1977 - Carnival mural, Florida 1985 - Nan one month after been battered, 1984 - "Kleenex Room" in whorehouse, NYC 1979.

La fotografia Nan one month after being battered forma parte de The ballad of the sexual dependancy. Por ser la imagen más conocida de Goldin, significa en tanto imagen, ya fetiche, el mito en el que se ha convertido Goldin.

El inicio de The ballad of the sexual dependancy corresponde a la época en la que Nan Goldin, tras abandonar su casa familiar y vivir en varias comunas, se muda al Bowery de Nueva York, en 1978. Goldin trabaja como camarera en un club y ese trabajo resulta decisivo para la realización de The Ballad. Goldin afirma en relación a su implicación con el contexto que retrata que sólo se puede hablar con verdadero conocimiento y empatía sobre aquello que se ha experimentado. Fiel a esa creencia documenta la vida nocturna del club que es el escenario de juergas, sexo, peleas, bailes, etcétera de la "familia", modo en el que Goldin llama a sus amigos, en el que ella se reconoce como parte.

Sobre los lazos que unían a la familia Goldin escribe: "en mi familia de amigos, hay un deseo de intimidad respectos a la familia biológica, pero también un deseo de algo más abierto. Los roles no están tan definidos. Hay relaciones duraderas. La gente se va, vuelve, pero estas separaciones se hacen sin la ruptura de la intimidad. Estamos unidos no por la sangre ni el lugar, sino por una moral similar, por la necesidad de vivir plenamente y en el momento. Por una incredulidad en el futuro, por un respeto similar por la honestidad, por una necesidad de empujar los límites y por una historia común" (Goldin, 1986:6)

A principios de los 80 aquellas fotografías comienzan a mostrarse como slideshows. Los shows se ofrecen originalmente en clubs de Nueva York que se acogen a la experimentación como el Raficks Underground cinema, el Mudd Club o más tarde el Maggie Smith 'Tin'Pan Alley. Este último fue uno de los locales donde más shows se ofrecieron (lugar que fue también el espacio de trabajo de artistas como Kiki Smith, Cookie Mueller o Barbara Ess). El grupo de amigos, la familia fotografiada se reúne para ver las fotos que Goldin les ha sacado, como si de un álbum familiar y el salón de una casa decimonónica se tratase.

Goldin decide realizar un álbum dónde no sólo muestra los momentos "felices", también se muestra maltratada, muestra a familiares teniendo relaciones sexuales, en el retrete, masturbándose; la artista opina que se guardan en privado las cosas equivocadas. ¿Por qué el sexo o las peleas deben ser un tabú en nuestras historias? ¿Por qué 
nunca suele haber una cámara en un entierro y, sin embargo, proliferan en una boda? Goldin considera que mostrar personas teniendo relaciones sexuales, muriéndose o mostrarse a ella misma maltratada, es decir, hacer lo privado público de una forma no pre-establecida, es un acto político. Recordemos la proclama, lo personal es político, del feminismo de los años 60-70.

El resultado de aquel primer álbum es el show que más adelante se ha llamado The Ballad of the sexual dependency. En 1986 la fotógrafa empieza a girar con The ballad que se proyecta en los festivales de cine de Berlín y de Edimburgo. The Ballad es la incorporación de Goldin al mundo del arte, un slide-show que se ha ido transformando continuamente a largo de 30 años. Esta característica de transformación continua que metaforiza The Ballad dificulta constantemente poder definir en términos claros la obra de Goldin.

De todas formas, se puede decir que Goldin estructura The Ballad en "temas" que se presentan sucesivamente (desnudos femeninos, desnudos masculinos, parejas en la cama, fiestas en el club, hombres solitarios, hombres en grupo, mujeres en compañía de mujeres, mujeres con sus hijos, tatuajes, etc.). Esta organización no es constante ni compacta y se exhibe acompañada de una banda sonora. Una mezcla de música pop, rock y clásica seleccionada en relación a las imágenes que acentúa las sensaciones que derivan del montaje: la alegría, la soledad, la incomprensión, la fusión o la fuerza.

Nan one month after being battered es una de las imágenes más paradigmáticas de The Ballad. En ella, como ya se ha dicho, Goldin muestra su lado más vulnerable. La foto, desde su crudeza nos conduce a la visión directa de un cardenal que es símbolo del emparejamiento llevado al límite. Con la fotografía vemos que entre la idea del amor romántico y la particularidad de la realidad de la vida de pareja, se produce una fricción que puede llevar a la violencia. Hemos visto cómo en las diferentes ediciones sobre la fotografía se constatan las diferentes narraciones realizadas por la artista sobre aquella experiencia vital.

Goldin habla así de la época que comparte con Brian, el hombre que la golpeó: "Durante algunos años, estuve profundamente ligada a un hombre. Estábamos emocionalmente muy unidos y la relación llegó a ser muy interdependiente. Los celos eran utilizados para inspirar pasión. Su concepto de relación estaba enraizado en el idealismo romántico de James Dean y Roy Orbison. Yo me moría por la dependencia, la adoración, la satisfacción, la seguridad, pero a veces sentía claustrofobia. Éramos adictos a la cantidad de amor que la relación nos proporcionaba. Éramos pareja. Las cosas entre nosotros empezaron a cambiar, pero ninguno de nosotros llevó a cabo la ruptura. El deseo constantemente nos reinspiraba al mismo tiempo que la insatisfacción aparecía de manera innegable. Nuestras obsesiones sexuales eran uno de nuestros ganchos. Una noche me pegó severamente hasta casi dejarme ciega" (Goldin, 1986: 8).

La tensión que conlleva esta foto deviene de un estado violento resultado de una relación de pareja, y ello representa, según la autora, un problema global. La foto nos muestra a una persona en concreto, Nan Goldin, en una localización particular, su habitación neoyorkina, pero trata asimismo sobre el espasmo que puede originarse cuando la experiencia propia de la vida no se identifica con las representaciones de la vida (del amor en este caso) que producen los mecanismos de poder. 
Por último, queremos destacar un cambio relevante acontecido en relación a Nan one month after been battered. En la exposición Scopophilia de Paris (2011) Goldin utiliza la fotografía dentro del diaporama presentado, sin embargo, en la exposición Nan Goldin. Berlin Work fotografien de Berlín (2011), no la utiliza. No obstante, aun no incorporando la conocida imagen, Goldin sí que introduce la experiencia del maltrato en la narrativa de Berlín a través de otra imagen realizada también en aquel momento, sin embargo es una imagen considerablemente menos conocida.

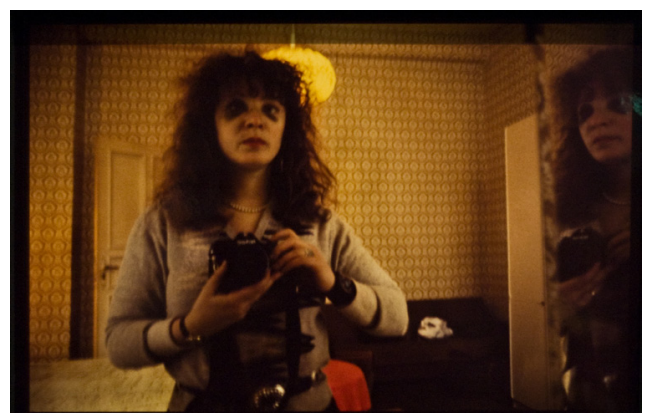

\section{A modo de conclusión}

Nos hemos preguntado si un artista, en este caso Nan Goldin, puede modelar su subjetividad diferenciándose de los discursos identitarios dominantes y al final de esta exposición no somos capaces de dar una sola y única respuesta a la cuestión planteada. De todas formas sí que estamos en disposición de mostrar, a modo de conclusión, posibles prácticas de liberación y de construcción de la identidad que observamos con este caso. Una identidad nómada y narrativa, que no se encuentra edificada previamente, sino que se va construyendo a medida que se construye la obra de arte.

Primero, destacamos el orden no cronológico de las narraciones de Goldin. Goldin presenta un tiempo no lineal, no progresivo. Tiempo que se relaciona con la concepción de Latour de un tiempo simultáneo, en la que los instantes destellan y el tiempo discurre de atrás adelante, de adelante atrás. (Latour, 2007:103) En esta apertura de la cronología clásica a la que asistimos, recordamos la interesante propuesta de Benjamin de realizar historia pero peinándola a contrapelo. "Toda verdadera comprensión forma un remolino. Nadar a tiempo contra la dirección de la corriente circular. Cómo en el arte lo decisivo es peinar la naturaleza a contrapelo" (Benjamin, 2004:839)

En segundo lugar, vemos que no podemos referirnos a Goldin en relación únicamente a una fotografía, y recordamos sus palabras cuando dice que en vez de una buena fotógrafa es una buena narradora. En este subrayamos la interrelación que se establece entre las imágenes en la edición de su obra, ya que excede, en muchos sentidos, los límites de la imagen fotográfica.

En tercer lugar, es indispensable pensar sobre la distancia que hay entre los sujetos fotografiados y la artista. Nan Goldin no es una voyeur, ella fotografía su fiesta, su familia, su historia. Y por lo tanto, muy al contrario del artista de la perspectiva, no 
está mirando a través de la ventana, sino que se encuentra dentro de la escena. La realidad representada y el sujeto que representa en absoluto se conciben separados. Esta cuestión de la poca-distancia, pues opinamos que siempre hay distancia, conlleva un conocimiento afectivo y subjetivo de lo fotografiado, que adelgaza la representación, o la desgarra, e imposibilita su categorización como una forma cerrada y glorificada. En este sentido, no podemos entender esa poca distancia sin el vínculo con el otro. Recordemos: yo es otro. Reivindicamos en estos tiempos en los que se responsabiliza al individuo en soledad de construir su identidad, la importancia del grupo, del vínculo; y extrapolando al arte, de la articulación, edición y la forma, aun siendo ésta nómada, narrativa y desgarrada.

En cuarto lugar, destacamos la deconstrucción, en el sentido derridiano, del álbum familiar clásico que supone la obra de Goldin. La artista no nos ofrece, tal lo hace Derrida con la metafísica, una verdad superior, anterior o exterior, sobre el álbum familiar, sino que trabajando desde el interior de la representación del álbum, cuestionando y sospechando sus narrativas habituales, realiza una representación de la familia bajo unos parámetros diferentes. Queremos subrayar que el resultado de su obra no es un archivo de imágenes que una representación familiar canónica descartaría por completo, ya que es más bien una mezcla que une representaciones inusuales con otras más estereotipadas.

En conclusión, podemos decir que la identidad de Goldin acontece en tanto que construida junto con la representación-arte y elegida entre otras vidas posibles. Es más, Goldin construye claramente una identidad en proceso en la medida en que, en sus últimos testimonios, reivindica la necesidad de cambio. Goldin en la conferencia ofrecida en el marco de la exposición The Hasselblad Award (Goteborg, 2007) dijo que quería dejar de ser Nan Goldin. Nan Goldin, considerada una de las fotógrafas clave de la fotografía documental contemporánea, se ha convertido en un símbolo de ella misma y para poder seguir siendo necesita escapar de la institución que su nombre constituye. Aquellas narrativas que en su día necesitaba, hoy, paradójicamente, la encarcelan. Opinamos que esta posición actual de la artista protege el punto de vista de nuestro estudio, ya que si Nan Goldin no mostrara la necesidad de dejar de ser Nan Goldin, de permutar y seguir con la continua búsqueda de prácticas de liberación, estaríamos analizando un sujeto ya casi objeto que no se ajusta a los condicionantes de identidad-obra que hemos tratado.

\section{Financiación}

Este trabajo es el resultado de una beca pre-doctoral financiada por el Gobierno Vasco (2004-08) y la participación en el proyecto de investigación CGV10/57 Imágenes en Tensión. Sobre la ausencia y la presencia del cuerpo en las prácticas de género financia por el Vicerrectorado de Investigación de la Universidad del País Vasco (2010-11). 


\section{Referencias}

Arfuch, L. (2002). El espacio biográfico. Dilemas de la subjetividad contemporánea. Buenos Aires: F.C.E

Bauman, Z. (2005). "Modernidad y ambivalencia". Beriain, J. (comp.) Las consecuencias perversas de la modernidad. Barcelona: Anthropos.

Bauman, Z. (2007). Modernidad líquida. México: Fondo de Cultura Económica

Benjamin, W. (2003). La obra de arte en la época de su reproductibilidad técnica. Mexico: Itaca

Benjamin, W. (2004). Libro de los pasajes. Madrid: Akal

Benjamin, W. (2005). "Pequeña historia de la fotografía" en Sobre la fotografía. Valencia: Pre-Textos (www.bio-design.com)

Benjamin, W. (2008). El narrador. Santiago de Chile: Metales Pesados (http://mimosa.pntic. mec.es)

Braidotti, R. (2004). Feminismo, diferencia sexual y subjetividad nómade. Barcelona: Gedisa

Deleuze, G. (1991). "Posdata sobre las sociedades de control" en Ferrer, C. (Comp.) El lenguaje literario, $\mathrm{T}^{\mathrm{o}}$ 2. Montevideo: Nordan

Didi- Huberman, G. (2010). Ante la imagen. Pregunta formulada a los fines de una historia del arte. Murcia: Cendeac.

Goldin, N. (1986). The ballad of the sexual dependency. Nueva York: Aperture Foundation

Goldin, N. (1993). The Other Side. Nueva York: Scalo Publishers

Goldin, N. (1997). In my life. Nueva York: Art [DVD]

Gómez, C. (2012). Identizazión: la construcción discursiva del individuo. Revista Arte, Individuo y Sociedad, 24 (1), 21-37.

Foucault, M. (2002). La hermenéutica del sujeto. Buenos Aires: FCE

Foucault, M. (2010). Vigilar y castigar. Buenos Aires: Siglo XXI

Heidegger, M. (2001). "La época de la imagen del mundo" en Caminos del Bosque (pp. 6390). Madrid: Alianza

Latour, B. (2007). Nunca fuimos modernos. Buenos Aires: Siglo XXI

Mirzoeff, N. (2003). Una introducción a la cultura visual. Barcelona: Paidós

Latour, B. (2007). Nunca fuimos modernos. Buenos Aires: Siglo XXI

Robin, R. (1996). Identidad, memoria y relato. La imposible narración del sí mismo. Buenos

Aires: Facultad de Ciencias Sociales CBC, serie Cuadernos de Posgrado

Lyotard, J.F. (2003). La Postmodernidad (explicada a los niños). Barcelona: Gedisa

Torregroza, E.J. (2004). Una introducción a Derrida. Bogota: Universidad Libre

Sontag, S. (2005). Sobre la fotografia, Madrid: Alfaguara

Taylor, C. (2006). Las fuentes del yo. La construcción de la identidad moderna. Barcelona: Paidós 